\title{
The role of anti-glutamic acid decarboxylase autoantibodies in mood disorders
}

\author{
Marco Liguori ${ }^{1}$, Mirko Manchiaa ${ }^{2,3}$, Leonardo Tondo ${ }^{4,5,6}$ \\ ${ }^{1}$ Laboratory of Microbiology and Immunology, G. Brotzu Hospital, 09121 Cagliari, Italy. \\ ${ }^{2}$ Department of Pharmacology, Dalhousie University, Halifax, NS B3H 4R2, Canada. \\ ${ }^{3}$ Department of Public Health, Clinical and Molecular Medicine, University of Cagliari, 09124 Cagliari, Italy. \\ ${ }^{4}$ Mood Disorder Lucio Bini Center, 09128 Cagliari, Italy. \\ ${ }^{5}$ Mood Disorder Lucio Bini Center, 00193 Rome, Italy. \\ ${ }^{6}$ McLean Hospital, Harvard Medical School, Boston 02115, MA, USA.
}

\section{A B S T R A C T}

Gamma-aminobutyric acid (GABA) possibly plays a causative role in mood disorders. This hypothesis originated with studies on the beneficial effect of valproate in mania and as a mood stabilizer. Since valproate is known for its action in increasing the level of GABA, it was indirectly suggested that decreasing levels of GABA were responsible for mood alterations. To identify factors causing the decreased levels of GABA, studies have concentrated on the activity of the enzyme L-glutamic acid decarboxylase (GAD), which catalyzes the transformation of glutamate to GABA, as a decreasing function of this enzyme induces lower levels of the neurotransmitter. Moreover, a very limited amount of research investigated the possible role of glutamic acid decarboxylase antibodies (GADA) in determining a decreased enzymatic function of GAD. If these findings are confirmed, it will be possible to improve diagnosis and treatment of mood disorders. In addition, if the presence of GADA is associated with a genetic trait, this would allow and facilitate early diagnoses.

Key words: Autoantibodies, bipolar disorder, gamma-aminobutyric acid, glutamate, L-glutamic-acid decarboxylase antibodies, mood disorders

\section{INTRODUCTION}

Mood disorders (MDs) are a relatively heterogeneous spectrum of psychiatric conditions. Differences in clinical course (single or recurrent episodes), severity and frequency of mood episodes, and population prevalence may characterize each syndrome [major depressive disorder (MDD), bipolar disorder (BD), cyclothymic disorder, dysthymia] within this broad nosological definition. These disorders generally have a substantial burden on the life of patients as well as on the public health systems. ${ }^{[1,2]}$ In fact, they have been increasingly recognized as leading causes of the worldwide burden of disease and disability. ${ }^{[3]}$

Corresponding Author: Dr. Leonardo Tondo,

Mood Disorder Lucio Bini Center, Via Cavalcanti 28,

09128 Cagliari, Italy.

E-mail: Itondo@mclean.harvard.edu

\begin{tabular}{|l|l|}
\hline \multicolumn{3}{|c|}{ Access this article online } \\
\hline Quick Response Code: & \\
\hline & Website: \\
\hline &
\end{tabular}

Despite the recent substantial progress in unraveling the complex biological underpinnings of MDs ${ }^{[4]}$ in which several biological pathways have been implicated,,$^{[5-7]}$ the pathophysiological mechanisms underlying these conditions are still unclear. Among these, it has been hypothesized that the gamma-aminobutyric acid (GABA) pathway takes the major role. ${ }^{[8]}$ Specifically, a low GABAergic function might be associated with the biological disruption leading to clinical symptomatology. Furthermore, specific alterations of the GABAergic molecular pathway might be present in patients manifesting distinct symptoms. One of these possible alterations may involve the role of autoantibodies for the L-glutamic acid decarboxylase (GAD), a key enzyme responsible of the synthesis of GABA.

We reviewed the limited research on the mechanisms responsible for the decreased GABAergic function in

This is an open access article distributed under the terms of the Creative Commons Attribution-NonCommercial-ShareAlike 3.0 License, which allows others to remix, tweak, and build upon the work non-commercially, as long as the author is credited and the new creations are licensed under the identical terms.

For reprints contact: nn_editor001@nnjournal.net

Cite this article as: Liguori M, Manchia M, Tondo $\mathrm{L}$. The role of anti-glutamic acid decarboxylase autoantibodies in mood disorders. Neuroimmunol Neuroinflammation 2015;2:237-43.

Received: 12-03-2015; Accepted: 26-05-2015 
MDs using the following key words: "gamma-amino butyric acid" OR "GABA" OR "L-glutamic-acid decarboxylase" OR "GAD” OR "autoantibodies" OR "GADA" AND "mood disorder" OR "major depressive disorder" OR "bipolar disorder" OR "depression". We found more than 200 publications and we selected all those with pertaining information on the association of any MD and abnormalities in the GABA pathway.

The aim of this review was to focus on: (1) reviewing briefly on the role of GABAergic pathway in MDs;

(2) describing the molecular functions of GAD;

(3) discussing the specific role of GAD as an important factor in the pathophysiology of MDs; and (4) providing future directions for the implementation of glutamic acid decarboxylase autoantibodies (GADA) screening in clinical practice.

\section{GABA IN MDs}

GABA is an inhibitory neurotransmitter present exclusively in the central nervous system (CNS). In a pivotal case series of 4 patients reported by Emrich et al. ${ }^{[9]}$ these authors demonstrated a marked mood-stabilizing effect of valproic acid (VPA) in the management of acute manic episodes as well as in the maintenance treatment of other 7 patients with recurrent episodes of manic or manic-schizoaffective psychosis, irresponsive to lithium prophylaxis. The beneficial effect of VPA suggested a role of the GABAergic pathway in MDD since this anticonvulsant leads to increased cerebral concentrations of GABA by inhibiting GABA-transaminase which degrades GABA and by facilitating the reuptake of released GABA into cells. VPA also stimulates synthesis of GABA by increasing the activity of glutamic acid decarboxylase. ${ }^{[10]}$ Subsequently, Emrich et al. ${ }^{[9]}$ discovered a lack of GABA in the CNS of mood disorder patients, which was restored by VPA, hypothesizing that modifications of this neurobiological pathway may be associated with MDs. A more recent study has suggested that in general, GABAergic anticonvulsants possess antimanic properties and that the specific antimanic effect of lithium is associated with an increased action of GABA. ${ }^{[11]}$ Furthermore, the same authors $^{[11]}$ suggested that the increased inhibitory neurotransmission induced by long-term lithium treatment counteracts the increased excitatory neurotransmission resulting from elevated levels of glutamate (GLU) which was detected in postmortem brain tissue of BD patients. Following the same line of investigation, GABA plasma level may represent a biological trait marker for MDD. Indeed, Petty and Schlesser ${ }^{[12]}$ found significantly decreased GABA plasma levels, compared to healthy controls, in $40 \%$ of depressed patients, but higher levels of plasma
GABA were found in manic BD individuals. Moreover, they observed that patients with different types of depressions, particularly those with familial loading, had plasma GABA levels significantly lower than control groups. Instead, GABA plasma levels in patients with reactive or bipolar depression did not differ from those of controls. ${ }^{[12]}$ As a result, it has been proposed that plasma levels of GABA might be a useful marker to predict the susceptibility to a depressive disorder in people with a family history of MDs. Furthermore, plasma levels of GABA may be specific and predictive of response to treatment, ${ }^{[13]}$ although GABA plasma level appears to show a low sensitivity as a test for depression.

Several other studies showed a decreased concentration of GABA in cerebrospinal fluid (CSF) of patients with severe depressive disorder. ${ }^{[14-17]}$ In particular, MDD patients over 40 years of age had significantly lower CSF levels of GABA than younger subjects. ${ }^{[17]}$ In addition, GABA levels in CSF of patients with depression and schizoaffective disorder are lower than those with schizophrenia or neurological conditions, ${ }^{[16]}$ Parkinson's disease, Huntington's disease, and dementia, all conditions which present at times depressive features. ${ }^{[18]}$ Of note, free GABA levels in CSF were lower in depressive disorders than in BD manic patients or healthy subjects. ${ }^{[16,17]}$ In addition to the association of GABA levels with depressive disorders, low levels of GABA have been also found in anxiety disorders ${ }^{[19,20]}$ and chronic migraine ${ }^{[21]}$ which is often comorbid with MDD. In a recent study, Mann et al. ${ }^{[20]}$ found an inverse correlation between psychic anxiety severity and free GABA levels in CSF, independently of age. Interestingly, benzodiazepines, the most used anti-anxiety agents, increased GABA synthesis in the CNS. ${ }^{[22]}$

Other proofs of the association between plasma GABA levels and depressive disorders may derive from the effect of electroconvulsive therapy (ECT) on severe refractory depression, since this treatment has been associated with a down-regulation of the GLU/GABA ratio (i.e. an increase in GABA and a decrease of GLU levels) in the hippocampus of rats. ${ }^{[23,24]}$ In fact, this measure of the GABAergic tone appears to be more informative than single neurotransmitter levels, given that GLU (a precursor of GABA) and GABA exert their effects in a neuromodulatory conjunction. ${ }^{[25]}$ Similar findings were observed in humans. GABA concentrations measured with proton magnetic resonance spectroscopy were significantly elevated in the occipital cortex of depressed patients following ECT. ${ }^{[26]}$ The increased levels of GABA in association with ECT may explain its antidepressant actions. In addition, increased GABA concentrations in the 
occipital cortex were also found during treatment of MDD with serotonergic antidepressants. ${ }^{[13]}$

Significantly lower levels of GABA were observed in the anterior cingulate cortex (ACC) of adolescents with MDD compared with healthy subjects. ${ }^{[27]}$ Levels were measured by the means of proton magnetic resonance spectroscopy and expressed as ratios to unsuppressed voxel tissue water (VTW). In this age group, significant differences were found for the ratio GABA/VTW in the ACC of adolescents with and without anhedonia but not in those nonanhedonic compared to healthy controls. ${ }^{[27]}$

\section{GABA PATHWAY-FOCUS ON GAD}

GABA is synthesized from GLU via decarboxylation by GAD, a pyridoxal phosphate-dependent enzyme. ${ }^{[28]}$ Studies of GAD began in the early 50s with the work of Roberts and Frankel, ${ }^{[29,30]}$ and Awapara ${ }^{[31]}$ who independently discovered that GABA is synthesized in GABAergic neurons in CNS. However, GAD and GABA were also detected in the pancreas where the latter is stored in synaptic-like vesicles in islet beta cells. ${ }^{[2-34]}$ GAD exists in two isoforms: one of a molecular size of $65 \mathrm{kDa}$ is termed $\mathrm{GAD}_{65}$, whilst the other, of $67 \mathrm{kDa}$, is termed $\mathrm{GAD}_{67}$. Each of them plays a distinct role: $\mathrm{GAD}_{65}$ is the product of a gene located on chromosome 10 whereas $\mathrm{GAD}_{67}$ gene is on chromosome $2 .^{[35-37]}$ These two proteins appear to be essential for maintaining homeostasis and viability of complex organisms. Studies carried out in $\mathrm{GAD}_{67}$ knockout mice showed a reduction in the levels of GABA and died at the birth of a severe cleft palate. ${ }^{[38]}$ Instead GAD $_{65}$ knockout mice presented normal basal levels of GABA and appear normal at birth but developed fatal seizures and anxiety-like phenotypes. ${ }^{[39]}$ The two isoforms were localized in different neuronal compartments. GAD ${ }_{65}$ lies primarily in axon terminals and synthesizes GABA for neuronal transmission. $\mathrm{GAD}_{67}$ is widely distributed throughout the neuron for the synthesis of GABA for general metabolic activity. ${ }^{[35,36,40]}$

\section{GAD IN MDs}

A substantial amount of evidence has suggested a role of GAD in MDs. Karolewicz et al. ${ }^{[41]}$ measured the levels of $\mathrm{GAD}_{65}$ and $\mathrm{GAD}_{67}$ in postmortem brain samples from the gray matter of left dorsolateral prefrontal cortex (DLPFC, Brodmann's Area 9) of MDD patients, treated and untreated with antidepressants. $\mathrm{GAD}_{65}$ and $\mathrm{GAD}_{67}$ were reduced in antidepressant-free MDD subjects compared to matched controls. This reduction was not present in MDD patients medicated with antidepressants at the time of death, suggesting that $\mathrm{GAD}_{65}$ and $\mathrm{GAD}_{67}$ might play a role in depressive syndromes. ${ }^{[41]}$ Fatemi et al. ${ }^{[42]}$ investigated the cerebellar levels of Reelin 410, 330 and $180 \mathrm{kDa}$, $\mathrm{GAD}_{65}$, and $\mathrm{GAD}_{67}$ in subjects with $\mathrm{BD}$, schizophrenia, MDD, and controls using the well-characterized Stanley Brain Consortium Collection. They found a reduction in levels of $\mathrm{GAD}_{65}$ and $\mathrm{GAD}_{67}$ proteins in all psychiatric subjects. These findings could explain increased blood and CSF GLU and glutamine levels in schizophrenic, ${ }^{[43,44]}$ and depressed subjects, ${ }^{[45]}$ probably due to an accumulation of these two precursor compounds of GABA. Indeed, normal production of $\mathrm{GAD}_{65}$ and $\mathrm{GAD}_{67}$, as well as of Reelin 410, 330 and $180 \mathrm{kDa}$, reflects normal GABAergic cell function in several parts of the brain including cerebellum. ${ }^{[46]}$ Of note, Reelin, a protein responsible for correct lamination of the CNS during the embryonic period, may be involved in the etiology of schizophrenia, BD, and autism. ${ }^{[47-54]}$ Remarkably, deficits in CNS levels of Reelin can affect memory processing, learning, synaptic organization, and cognition in the adult brain. ${ }^{[55]}$

Interestingly, $\mathrm{GAD}_{67}$ appeared to be a promising biomarker for $\mathrm{BD}$ and schizophrenia since it discriminated these illnesses among a number of psychiatric conditions with relatively high specificity and sensitivity. ${ }^{[56]}$ Moreover, decreased levels of GAD were found in the postmortem left DLPFC of BD patients compared with MDD individuals and controls, giving rise to the possibility of differentiating the brain areas involved in unipolar and bipolar depression. Heckers and colleagues first made the description of the distribution of $\mathrm{GAD}_{65}$ and $\mathrm{GAD}_{67}$ mRNA-positive neurons in the human hippocampus. ${ }^{[57]}$ They found that abnormalities of hippocampal GAD expression are more prominent in BD than in schizophrenia, whereas another study showed a larger reduction of $\mathrm{GAD}_{67}$ mRNA-containing neurons in $\mathrm{BD}$ patients than in those with schizophrenia. ${ }^{[58]}$ Of interest is the evidence that decreased $\mathrm{GAD}_{67}$ expression leads to a reduction of levels of GABA, with a net effect of a reduced GABAergic inhibitory control over glutamatergic cells. Therefore, it has been hypothesized that $\mathrm{GAD}_{67}$ levels could be a surrogate marker for psychosis liability ${ }^{[59]}$ and pharmacological agents that raise $\mathrm{GAD}_{67}$ expression levels could represent novel targets for antipsychotic therapy. ${ }^{[59]}$ Taken together, these findings demonstrate that GAD might have a role in modulating the psychopathological presentation in a distinct subset of patients with MDs, possibly those with more prominent mood-congruent or incongruent psychotic features. 


\section{GADA IN MDs}

As we have previously described, MDs may be associated with low levels of GABA following a decreased activity of GAD. It would, therefore, be reasonable to assume that its antibody, GADA, can somehow be involved in the pathogenesis of MD inhibiting GABAergic function. Support to this hypothesis came from research on the Stiff Person syndrome (SPS). In 1956, Moersh and Woltman ${ }^{[60]}$ observed this syndrome in 14 patients over the age of 35 years, characterized by fluctuating rigidity and spasms without pyramidal tract dysfunction, or any other known neurologic disorders that could explain the stiffness. Moreover, Levy et al.$^{\left[{ }^{[1]}\right.}$ observed muscular rigidity and episodic spasms superimposed on the rigidity in 20 consecutive patients. They reported as the hallmark sign the continuous contraction of the agonist and antagonist muscles in the trunk that caused hyperlordosis and respiratory problems. Interestingly, several patients initially received a tentative diagnosed of the psychogenic process because their presentation was dominated by task-specific phobias and their stiffness was precipitated by unexpected noises or mental anticipation. In addition, seizures were observed in $10 \%$ of cases. Anxious and depressive symptoms in SPS can be explained by alterations in GABAergic neurotransmission. It was demonstrated that stiffness was caused by a reduction of GABA or glycine, the two main inhibitory neurotransmitters and was improved by drugs increasing brain levels of GABA, such as diazepam or VPA. ${ }^{[62]}$ It was found later that up to $65 \%$ of patients may have antibodies GADA against both $\mathrm{GAD}_{65}$ and $\mathrm{GAD}_{67}: \mathrm{GAD}_{65}$ and

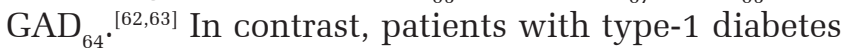
had anti-GAD antibody titers 50 times lower than those of patients with SPS. The epitope of the GAD antigen may also differ between patients with type-1 diabetes and those with the SPS. ${ }^{[64]}$ These autoantibodies cause a functional impairment in the synthesis of GABA in persons with SPS; therefore, GADA should be considered to play a pathogenic role in this disease. In this context, it is noteworthy that patients with type-1 diabetes mellitus, particularly those with poor glycemic control, often undergo CNS related changes with low cognitive performance and depression. Short-term treatment of depression in patients with diabetes improves their dysphoria and other signs and symptoms of depression..$^{[65]}$ In Batten disease, a rare genetic neurodegenerative disorder characterized by severe mental impairment, Chattopadhyay et al. ${ }^{[66]}$ studied a mouse model reporting the presence of an autoantibody to $\mathrm{GAD}_{65}$. These authors hypothesized that an autoimmune response to $\mathrm{GAD}_{65}$ may contribute to a preferential loss of GABAergic neurons associated with Batten disease. ${ }^{[66]}$ Several groups observed an increased prevalence of autoimmune disease and/or autoantibodies in patients with BD, including autoimmune thyroiditis and autoimmune atrophic gastritis. More specifically, Padmos et al. ${ }^{[67]}$ studied 239 patients with DSM-IV BD, 74 patients with DSM-IV schizophrenia, and 220 healthy control subjects for detection of $\mathrm{GAD}_{65}, \mathrm{GAD}_{67}$, and thyroperoxidase antibodies (TPOA), formerly reported to have an increased prevalence in patients with $\mathrm{BD}$. The presence of $\mathrm{GAD}_{65}$ (and not that of TPOA and $\mathrm{H}^{+} / \mathrm{K}^{+}$adenosine triphosphatase antibody) tended to be associated with BD. ${ }^{[67]}$ Psychiatric symptoms, such as depression and anxiety, may be prominent, resulting in an incorrect diagnosis. Culav-Sumic et al. ${ }^{[68]}$ described a case of a woman who initially presented with anxious depression and remained resistant to treatment with different classes of antidepressants and additional therapy with lithium and atypical antipsychotics until the detection of GADA supported the diagnosis of SPS. Even the benefit obtained with immunosuppressive treatment with methylprednisolone might support the findings of anxious and depressive symptoms in SPS following the abnormal GABAergic neurotransmission. Finally, Yarlagadda et al. ${ }^{[69]}$ found elevated, but not statistically significant, levels of GADA in 12 patients with chronic psychotic disorders (schizophrenia and schizoaffective disorder) compared to healthy controls suggesting a link between antibodies to $\mathrm{GAD}_{65}$ and chronic psychotic disorders as well as an autoimmune mechanism in the pathogenesis of these disorders.

\section{FUTURE DIRECTIONS}

Existing evidence supports the role of GADA in the pathophysiology of a set of heterogeneous disorders that share clinical manifestations of severe motor, behavioral and mood symptoms. It is of interest that BD patients might present increasing titers of GADA compared to healthy controls. It is conceivable (and remains to be tested) that GADA levels might be one of the causative phenotypic manifestations of BD. Indeed, findings of a decreased GABAergic tone during mania might be explained by the diminished synthesis of this inhibitory neurotransmitter due to the action of GADA. Carefully designed studies targeting subsets of BD patients could clarify this hypothesis. The implications for diagnosis and treatment are significant. Detecting GADA in peripheral tissues is a feasible procedure that may assist the diagnostic assessment and depending on the specificity and sensitivity, could be considered a screening test for BD patients. Moreover, GADA could be tested as a marker of response to treatment, particularly to GABAergic agents, such as VPA. Further works are needed to identify the exact pathophysiological 
mechanism through which GADA develop and to clarify whether a genetic liability may play a role. Regarding the latter, it is of interest that a recent pharmacogenomic analysis ${ }^{[70]}$ in Han Chinese BD patients found a strong association between glutamate decarboxylase-like protein 1 (GADL1) gene and response to lithium. The physiological functions of GADL1 gene are not clear, which may be, however, similar to those of GAD.

\section{CONCLUSION}

Several studies found that a decrease of brain GABA levels in mood disorder cases can be associated with manic or depressive states. This apparent incongruity may indicate more a mood-stabilizing role of GABA rather than an action on different mood phases. It remains to be established why GABA levels, both in CNS and peripherally, might also present elevation in specific clinical cases. In an attempt to clarify the mechanisms behind these abnormal levels of GABA in the brain, it has been hypothesized an abnormal function of the enzyme GAD that catalyzes the conversion from GLU to GABA. A weak action of this enzyme would justify decreased levels of the neurotransmitter. The aforementioned lines of evidence suggest that the autoantibody to GAD may be a possible causative factor. If this is confirmed, a relatively simple test to assess the level of GADA may provide a better diagnosis of a mood disorder and to improve treatment. If an abnormal level of this antibody is present as a trait rather than being associated with illness episodes, it would allow an early diagnosis of such prevalent and disabling disorder.

Financial support and sponsorship Nil.

\section{Conflicts of interest}

There are no conflicts of interest.

\section{REFERENCES}

1. Gustavsson A, Svensson M, Jacobi F, Allgulander C, Alonso J, Beghi E, Dodel R, Ekman M, Faravelli C, Fratiglioni L, Gannon B, Jones DH, Jennum P, Jordanova A, Jonsson L, Karampampa K, Knapp M, Kobelt G, Kurth T, Lieb R, Linde M, Ljungcrantz C, Maercker A, Melin B, Moscarelli M, Musayev A, Norwood F, Preisig M, Pugliatti M, Rehm J, Salvador-Carulla L, Schlehofer B, Simon R, Steinhausen HC, Stovner LJ, Vallat JM, Van den Bergh P, van Os J, Vos P, Xu W, Wittchen HU, Jonsson B, Olesen J, Group CD. Cost of disorders of the brain in Europe 2010. Eur Neuropsychopharmacol 2011;21:718-79.

2. Kessler RC. The global burden of anxiety and mood disorders: putting the European Study of the Epidemiology of Mental Disorders (ESEMeD) findings into perspective. $J$ Clin Psychiatry 2007;68 Suppl 2:10-9.

3. World Health Organization. The Global Burden of Disease: 2004 Update. Geneva: The World Health Organization; 2008.
4. Duman RS. Pathophysiology of depression and innovative treatments: remodeling glutamatergic synaptic connections. Dialogues Clin Neurosci 2014;16:11-27.

5. Berns GS, Nemeroff CB. The neurobiology of bipolar disorder. Am J Med Genet C Semin Med Genet 2003;123C: 76-84.

6. Jun C, Choi Y, Lim SM, Bae S, Hong YS, Kim JE, Lyoo IK Disturbance of the glutamatergic system in mood disorders. Exp Neurobiol 2014;23:28-35.

7. Andreazza AC, Young LT. The neurobiology of bipolar disorder: identifying targets for specific agents and synergies for combination treatment. Int J Neuropsychopharmacol 2014;17:1039-52.

8. Brambilla P, Perez J, Barale F, Schettini G, Soares JC. GABAergic dysfunction in mood disorders. Mol Psychiatry 2003;8:721-37, 715.

9. Emrich HM, von Zerssen D, Kissling W, Moller HJ, Windorfer A. Effect of sodium valproate on mania. The GABA-hypothesis of affective disorders. Arch Psychiatr Nervenkr 1980;229:1-16.

10. Chiu CT, Wang Z, Hunsberger JG, Chuang DM. Therapeutic potential of mood stabilizers lithium and valproic acid: beyond bipolar disorder. Pharmacol Rev 2013;65:105-42.

11. Lan MJ, McLoughlin GA, Griffin JL, Tsang TM, Huang JT, Yuan P, Manji H, Holmes E, Bahn S. Metabonomic analysis identifies molecular changes associated with the pathophysiology and drug treatment of bipolar disorder. Mol Psychiatry 2009;14:269-79.

12. Petty F, Schlesser MA. Plasma GABA in affective illness. A preliminary investigation. J Affect Disord 1981;3:339-43

13. Sanacora G, Mason GF, Rothman DL, Krystal JH. Increased occipital cortex GABA concentrations in depressed patients after therapy with selective serotonin reuptake inhibitors. Am J Psychiatry 2002;159:663-5.

14. Manyam NV, Katz L, Hare TA, Gerber JC 3rd, Grossman MH. Levels of gamma-aminobutyric acid in cerebrospinal fluid in various neurologic disorders. Arch Neurol 1980;37:352-5.

15. Gold BI, Bowers MB Jr, Roth RH, Sweeney DW. GABA levels in CSF of patients with psychiatric disorders. Am $J$ Psychiatry 1980;137:362-4.

16. Gerner RH, Hare TA. CSF GABA in normal subjects and patients with depression, schizophrenia, mania, and anorexia nervosa. Am J Psychiatry 1981;138:1098-101.

17. Gerner RH, Fairbanks L, Anderson GM, Young JG, Scheinin M, Linnoila M, Hare TA, Shaywitz BA, Cohen DJ. CSF neurochemistry in depressed, manic, and schizophrenic patients compared with that of normal controls. Am J Psychiatry 1984;141:1533-40.

18. Enna SJ, Stern LZ, Wastek GJ, Yamamura HI. Cerebrospinal fluid gamma-aminobutyric acid variations in neurological disorders. Arch Neurol 1977;34:683-5.

19. Rimon R, Lepola U, Jolkkonen J, Halonen T, Riekkinen P. Cerebrospinal fluid gamma-aminobutyric acid in patients with panic disorder. Biol Psychiatry 1995;38:737-41.

20. Mann JJ, Oquendo MA, Watson KT, Boldrini M, Malone KM, Ellis SP, Sullivan G, Cooper TB, Xie S, Currier D. Anxiety in major depression and cerebrospinal fluid free gamma-aminobutyric acid Depress Anxiety 2014;31:814-21.

21. Vieira DS, Naffah-Mazacoratti MG, Zukerman E, Senne Soares CA Alonso EO, Faulhaber MH, Cavalheiro EA, Peres MF. Cerebrospinal fluid GABA levels in chronic migraine with and without depression. Brain Res 2006;1090:197-201.

22. Baldessarini RJ. Chemotherapy in Psychiatry. 1st ed. New York: Springer; 2013.

23. Sartorius A, Mahlstedt MM, Vollmayr B, Henn FA, Ende G. Elevated spectroscopic glutamate/gamma-amino butyric acid in rats bred for learned helplessness. Neuroreport 2007;18:1469-73.

24. Luo J, Min S, Wei K, Li P, Dong J, Liu YF. Propofol protects against impairment of learning-memory and imbalance of hippocampal Glu/GABA induced by electroconvulsive shock in depressed rats. $J$ Anesth 2011;25:657-65.

25. Fosse R, Read J. Electroconvulsive treatment: hypotheses about mechanisms of action. Front Psychiatry 2013;4:94.

26. Sanacora G, Mason GF, Rothman DL, Hyder F, Ciarcia JJ, Ostroff RB, Berman RM, Krystal JH. Increased cortical GABA 
concentrations in depressed patients receiving ECT. Am J Psychiatry 2003;160:577-9.

27. Gabbay V, Mao X, Klein RG, Ely BA, Babb JS, Panzer AM, Alonso CM, Shungu DC. Anterior cingulate cortex gamma-aminobutyric acid in depressed adolescents: relationship to anhedonia. Arch Gen Psychiatry 2012;69:139-49.

28. Martin DL, Martin SB, Wu SJ, Espina N. Cofactor interactions and the regulation of glutamate decarboxylase activity. Neurochem Res 1991;16:243-9.

29. Roberts E, Frankel S. Glutamic acid decarboxylase in brain. J Biol Chem 1951;188:789-95.

30. Roberts E, Frankel S. Gamma-aminobutyric acid in brain: its formation from glutamic acid. J Biol Chem 1950;187:55-63.

31. Awapara J. Occurrence of free gamma-aminobutyric acid in brain and its formation from L-glutamic acid. Tex Rep Biol Med 1950;8:443-7.

32. Reetz A, Solimena M, Matteoli M, Folli F, Takei K, De Camilli P. GABA and pancreatic beta-cells: colocalization of glutamic acid decarboxylase (GAD) and GABA with synaptic-like microvesicles suggests their role in GABA storage and secretion. EMBO $J$ 1991;10:1275-84

33. Sorenson RL, Garry DG, Brelje TC. Structural and functional considerations of GABA in islets of Langerhans. Beta-cells and nerves. Diabetes 1991;40:1365-74.

34. Jun HS, Khil LY, Yoon JW. Role of glutamic acid decarboxylase in the pathogenesis of type 1 diabetes. Cell Mol Life Sci 2002;59:1892-901.

35. Erlander MG, Tillakaratne NJ, Feldblum S, Patel N, Tobin AJ. Two genes encode distinct glutamate decarboxylases. Neuron 1991;7:91-100

36. Kaufman DL, Houser CR, Tobin AJ. Two forms of the gamma-aminobutyric acid synthetic enzyme glutamate decarboxylase have distinct intraneuronal distributions and cofactor interactions. J Neurochem 1991;56:720-3.

37. Soghomonian JJ, Laprade N. Glutamate decarboxylase (GAD67 and GAD65) gene expression is increased in a subpopulation of neurons in the putamen of parkinsonian monkeys. Synapse 1997;27:122-32.

38. Asada H, Kawamura Y, Maruyama K, Kume H, Ding RG, Kanbara N, Kuzume H, Sanbo M, Yagi T, Obata K. Cleft palate and decreased brain gamma-aminobutyric acid in mice lacking the 67-kDa isoform of glutamic acid decarboxylase. Proc Natl Acad SciU S A 1997;94:6496-9.

39. Asada H, Kawamura Y, Maruyama K, Kume H, Ding R, Ji FY, Kanbara N, Kuzume H, Sanbo M, Yagi T, Obata K. Mice lacking the $65 \mathrm{kDa}$ isoform of glutamic acid decarboxylase (GAD65) maintain normal levels of GAD67 and GABA in their brains but are susceptible to seizures. Biochem Biophys Res Commun 1996;229:891-5

40. Martin DL, Rimvall K. Regulation of gamma-aminobutyric acid synthesis in the brain. J Neurochem 1993;60:395-407.

41. Karolewicz B, Maciag D, O'Dwyer G, Stockmeier CA, Feyissa AM, Rajkowska G. Reduced level of glutamic acid decarboxylase- $67 \mathrm{kDa}$ in the prefrontal cortex in major depression. Int J Neuropsychopharmacol 2010;13:411-20.

42. Fatemi SH, Stary JM, Earle JA, Araghi-Niknam M, Eagan E. GABAergic dysfunction in schizophrenia and mood disorders as reflected by decreased levels of glutamic acid decarboxylase 65 and $67 \mathrm{kDa}$ and Reelin proteins in cerebellum. Schizophr Res 2005;72:109-22.

43. Labarca R, Silva H, Jerez S, Ruiz A, Renterias P, Ogalde C, Bustos G. Effects of haloperidol on CSF glutamate levels in drug-naive schizophrenic patients. Schizophr Res 1995;16:83-5.

44. Tortorella A, Monteleone P, Fabrazzo M, Viggiano A, De Luca L, Maj M. Plasma concentrations of amino acids in chronic schizophrenics treated with clozapine. Neuropsychobiology 2001;44:167-71.

45. Levine J, Panchalingam K, Rapoport A, Gershon S, McClure RJ, Pettegrew JW. Increased cerebrospinal fluid glutamine levels in depressed patients. Biol Psychiatry 2000;47:586-93.

46. Pesold C, Impagnatiello F, Pisu MG, Uzunov DP, Costa E, Guidotti A,
Caruncho HJ. Reelin is preferentially expressed in neurons synthesizing gamma-aminobutyric acid in cortex and hippocampus of adult rats. Proc Natl Acad Sci U S A 1998;95:3221-6.

47. Fatemi SH, Emamian ES, Kist D, Sidwell RW, Nakajima K, Akhter P, Shier A, Sheikh S, Bailey K. Defective corticogenesis and reduction in Reelin immunoreactivity in cortex and hippocampus of prenatally infected neonatal mice. Mol Psychiatry 1999;4:145-54.

48. Fatemi SH, Earle JA, McMenomy T. Reduction in Reelin immunoreactivity in hippocampus of subjects with schizophrenia, bipolar disorder and major depression. Mol Psychiatry 2000;5:654-63, 571.

49. Fatemi SH, Stary JM, Halt AR, Realmuto GR. Dysregulation of Reelin and Bcl-2 proteins in autistic cerebellum. J Autism Dev Disord 2001;31:529-35.

50. Fatemi SH, Kroll JL, Stary JM. Altered levels of Reelin and its isoforms in schizophrenia and mood disorders. Neuroreport 2001;12:3209-15.

51. Fatemi SH. Reelin mutations in mouse and man: from reeler mouse to schizophrenia, mood disorders, autism and lissencephaly. Mol Psychiatry 2001;6:129-33.

52. Fatemi SH. The role of Reelin in pathology of autism. Mol Psychiatry 2002; 7:919-20

53. Fatemi SH, Halt AR, Stary JM, Kanodia R, Schulz SC, Realmuto GR Glutamic acid decarboxylase 65 and $67 \mathrm{kDa}$ proteins are reduced in autistic parietal and cerebellar cortices. Biol Psychiatry 2002;52:805-10.

54. Fatemi SH, Stary JM, Egan EA. Reduced blood levels of Reelin as a vulnerability factor in pathophysiology of autistic disorder. Cell Mol Neurobiol 2002;22:139-52.

55. Weeber EJ, Beffert U, Jones C, Christian JM, Forster E, Sweatt JD, Herz J. Reelin and ApoE receptors cooperate to enhance hippocampal synaptic plasticity and learning. $J$ Biol Chem 2002;277:39944-52.

56. Knable MB, Barci BM, Bartko JJ, Webster MJ, Torrey EF. Molecular abnormalities in the major psychiatric illnesses: classification and regression tree (CRT) analysis of post-mortem prefrontal markers. Mol Psychiatry 2002;7:392-404.

57. Heckers S, Stone D, Walsh J, Shick J, Koul P, Benes FM. Differential hippocampal expression of glutamic acid decarboxylase 65 and 67 messenger RNA in bipolar disorder and schizophrenia. Arch Gen Psychiatry 2002;59:521-9.

58. Woo TU, Walsh JP, Benes FM. Density of glutamic acid decarboxylase 67 messenger RNA-containing neurons that express the $\mathrm{N}$-methyl-D-aspartate receptor subunit NR2A in the anterior cingulate cortex in schizophrenia and bipolar disorder. Arch Gen Psychiatry 2004;61:649-57.

59. Kalkman HO, Loetscher E. GAD (67): the link between the GABA-deficit hypothesis and the dopaminergic- and glutamatergic theories of psychosis. J Neural Transm 2003;110:803-12.

60. Moersch FP, Woltman HW. Progressive fluctuating muscular rigidity and spasm ("stiff-man" syndrome); report of a case and some observations in 13 other cases. Proc Staff Meet Mayo Clin 1956;31:421-7.

61. Levy LM, Dalakas MC, Floeter MK. The stiff-person syndrome: an autoimmune disorder affecting neurotransmission of gamma-aminobutyric acid. Ann Intern Med 1999;131:522-30.

62. Solimena M, Folli F, Denis-Donini S, Comi GC, Pozza G, De Camilli P, Vicari AM. Autoantibodies to glutamic acid decarboxylase in a patient with stiff-man syndrome, epilepsy, and type I diabetes mellitus. N Engl J Med 1988;318:1012-20.

63. Ellis TM, Atkinson MA. The clinical significance of an autoimmune response against glutamic acid decarboxylase. Nat Med 1996;2:148-53.

64. Dinkel K, Meinck HM, Jury KM, Karges W, Richter W. Inhibition of gamma-aminobutyric acid synthesis by glutamic acid decarboxylase autoantibodies in stiff-man syndrome. Ann Neurol 1998;44:194-201.

65. Musselman DL, Betan E, Larsen H, Phillips LS. Relationship of depression to diabetes types 1 and 2: epidemiology, biology, and 
treatment. Biol Psychiatry 2003;54:317-29.

66. Chattopadhyay S, Ito M, Cooper JD, Brooks AI, Curran TM, Powers JM, Pearce DA. An autoantibody inhibitory to glutamic acid decarboxylase in the neurodegenerative disorder Batten disease. Hum Mol Genet 2002;11:1421-31.

67. Padmos RC, Bekris L, Knijff EM, Tiemeier H, Kupka RW, Cohen D, Nolen WA, Lernmark A, Drexhage HA. A high prevalence of organ-specific autoimmunity in patients with bipolar disorder. Biol Psychiatry 2004;56:476-82

68. Culav-Sumic J, Bosnjak I, Pastar Z, Jukic V. Anxious depression and the stiff-person plus syndrome. Cogn Behav Neurol 2008;21:242-5
69. Yarlagadda A, Helvink B, Chou C, Clayton AH. Blood brain barrier: the role of GAD antibodies in psychiatry. Psychiatry (Edgmont) 2007;4:57-9.

70. Chen CH, Lee CS, Lee MT, Ouyang WC, Chen CC, Chong MY, Wu JY, Tan HK, Lee YC, Chuo LJ, Chiu NY, Tsang HY, Chang TJ, Lung FW, Chiu $\mathrm{CH}$, Chang $\mathrm{CH}$, Chen YS, Hou YM, Chen CC, Lai TJ, Tung CL, Chen CY, Lane HY, Su TP, Feng J, Lin JJ, Chang CJ, Teng PR, Liu CY, Chen CK, Liu IC, Chen JJ, Lu T, Fan CC, Wu CK, Li CF, Wang KH, Wu LS, Peng HL, Chang CP, Lu LS, Chen YT, Cheng AT, Bipolar CT. Variant GADL1 and response to lithium therapy in bipolar I disorder. $N$ Engl $J$ Med 2014;370:119-28. 